Bul. Agrohorti 4(3): 257-265 (2016)

\title{
Penyadapan Tanaman Karet (Hevea brasiliensis Muell Arg.) di Kebun Sumber Tengah, Jember, Jawa Timur
}

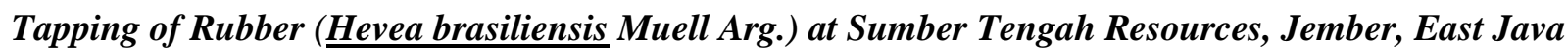

\author{
Muhamad Ismail $^{1}$ dan Supijatno ${ }^{1^{*}}$ \\ ${ }^{1}$ Departemen Agronomi dan Hortikultura, Fakultas Pertanian, Institut Pertanian Bogor \\ (Bogor Agricultural University), Jl. Meranti, Kampus IPB Darmaga, Bogor 16680, Indonesia \\ Telp. \& Faks.62-251-8629353 e-mail agronipb@indo.net.id \\ *Penulis untuk korespondensi: supijatno@yahoo.com
}

Disetujui 14 November 2016/ Published online 8 Desember 2016

\begin{abstract}
The objective of this internship is to increase technical and managerial skill. The internship was conducted from February until May 2012 at Sumber Tengah Estate, Jember, East Java. The methods of this internship are direct and indirect methods. The direct methods are conducted by following work practice as field worker and foreman assistant, while the indirect methods are conducted by collecting information from resources archives and literature review. Direct method that were observed include: tapping capacity, tapping classification, bark consumtion, stimulant aplication, tapping panel dryness (TPD) and transport systems. The average percentage of trees tapped in Afdeling Sumber Jambe is 90.98\%. Age, education, and experience of tappers does not determine tapper class. The depth of tapping at Afdeling Sumber Jambe is 0.9-1.2 mm/tapping, appropriate with the recommendations of Getas Rubber Research Center that is 1-1.5 $\mathrm{mm} / \mathrm{tapping}$. The accuracy of liquid stimulant doses used at Afdeling Sumber Jambe was appropriate standards recommended that is $1 \mathrm{~g} /$ tree/month but the time of the application is not in accordance with the tapping system used. Implementation of the transport system is quite good from latex collection in the field to the colllection place up to the processing factory. Latex and lump carrying capacity at Afdeling Sumber Jambe is enough.
\end{abstract}

Keywords : bark consumtion, stimulant, tapping

ABSTRAK

Tujuan dari kegiaatan magang adalah untuk meningkatkan keahlian teknik dan manajerial. Kegiatan magang dilaksanakan dari bulan Februari sampai Mei 2012 di Perkebunan Sumber Tengah, Jember, Jawa Timur. Metode magang yang digunakan adalah metode langsung dan tidak langsung. Pengumpulan data yang dilaksanakan pada kegiatan magang menggunakan metode langsung (data primer) dan metode tidak langsung (data sekunder). Data primer adalah informasi yang didapatkan secara langsung melalui pengamatan di lapangan maupun diskusi dengan KHL, mandor dan asisten kebun, sedangkan data sekunder diperoleh dari berbagai literatur. Sistem penyadapan tanaman karet yang dilakukan di Kebun Sumber Tengah sudah cukup baik mulai dari kapasitas penyadapan sampai sistem pengangkutan. Rata-rata persentase pohon tersadap di Afdeling Sumber Jambe yaitu 90.98\%. Usia, pendidikan, dan pengalaman penyadap tidak menentukan kelas sadap. Kedalaman sadap di Afdeling Sumber Jambe yaitu 0.9-1.2 $\mathrm{mm} / \mathrm{sadap}$ sudah sesuai dengan rekomendasi dari Balit Getas yaitu 1-1.5 mm/sadap. Ketepatan dosis stimulansia cair yang digunakan di Afdeling Sumber Jambe sudah sesuai standar yang dianjurkan yaitu 1 g/pohon/bulan tetapi ketepatan waktu aplikasi belum sesuai dengan sistem sadap yang digunakan. Terdapat beberapa aplikasi stimulansia gas yang tidak sesuai dengan standar. Kapasitas pengangkutan lateks dan lump di Afdeling Sumber Jambe sudah cukup.

Kata kunci: konsumsi kulit, penyadapan, stimulan 


\section{PENDAHULUAN}

Tanaman karet merupakan salah satu komoditas perkebunan unggulan Indonesia. Menurut Data Statistik Perkebunan Indonesia, luas areal perkebunan karet di Indonesia terus mengalami peningkatan. Pada tahun 2005, luas areal penanaman karet di Indonesia 3279391 ha, meningkat menjadi 3435270 ha pada tahun 2009. Produksi karet di Indonesia juga meningkat, yaitu 2.2 juta ton pada tahun 2005 , menjadi 2.4 juta ton pada tahun 2009. Tingkat produktivitas rata-rata tanaman karet di Indonesia pada tahun 2009 yaitu 0.71 ton/ha dan diperkirakan menjadi 0.76 ton/ha pada tahun 2011 (Ditjenbun, 2011).

Tanaman Karet (Hevea brasiliensis Muell Arg.) mempunyai habitat asli di daerah Amerika Selatan, terutama Brazil yang beriklim tropis, oleh karena itu karet juga cocok ditanam di daerah tropis lainnya (Heru dan Andoko, 2010). Tanaman karet dapat tumbuh di Indonesia terutama di daerah yang baik menyangkut kesesuaian lahan, ketinggian, keadaan iklim, kelembapan, dan suhu (Tarmizi, 2007). Tanaman karet tumbuh pada daerah yang terbatas sampai $20^{\circ}$ atau $25^{\circ}$ di sekitar ekuator (Polhamus, 1962). Daerah tropis yang baik untuk ditanami karet meliputi $15^{\circ} \mathrm{LU}-15^{\circ} \mathrm{LS}$. Tanaman karet akan terhambat pertumbuhan dan produksinya bila ditanam di luar daerah tersebut (Setyamidjaja, 1993).

Tanaman karet dieksploitasi atau dipanen lateksnya dengan cara disadap, yaitu mengiris kulit batang sehingga sebagian besar sel pembuluh lateks terpotong dan cairan lateks yang terdapat di dalamnya menetes keluar. Produktivitas kebun karet ditentukan oleh jenis klon, umur tanaman, tingkat kesesuaian lahan, dan sistem eksploitasi yang diterapkan. Menurut Setyamidjaja (1993).Lateks dibentuk dan terakumulasi dalam sel-sel pembuluh lateks yang tersusun pada setiap jaringan bagian tanaman, namun penyadapan yang menguntungkan hanya dilakukan pada kulit batang dengan sistem eksploitasi tertentu.

Sistem eksploitasi adalah rangkaian sistem sadap yang diterapkan sepanjang periode produksi tanaman karet. Sistem eksploitasi yang diterapkan menentukan produktivitas kebun karet karena berhubungan dengan tataguna kulit dan proses fisiologi lateks. Pelaksanaan sistem eksploitasi yang benar dapat menjamin produktivitas yang tinggi dan berkelanjutan. Sebaliknya pelaksanaan sistem eksploitasi yang salah dapat mengakibatkan produktivitas yang rendah dan umur ekonomis tanaman yang pendek.

Secara umum tujuan magang adalah meningkatkan relevansi atau keterkaitan dan kesesuaian antara proses pendidikan dengan lapangan pekerjaan. Selain itu, kegiatan ini diharapkan dapat meningkatkan kemampuan mahasiswa sebagai calon tenaga kerja dalam memahami dan menghayati proses kerja secara nyata di lapangan. Tujuan magang secara khusus adalah mempelajari dan mengetahui sistem penyadapan tanaman karet di Kebun Sumber Tengah, Jember, Jawa Timur. Setelah mengikuti pekerjaan sesuai dengan prosedur dan norma yang telah ditetapkan, diharapkan dapat meningkatkan keterampilan serta pengalaman kerja mahasiswa baik teknis maupun manajerial secara langsung di lapangan.

\section{BAHAN DAN METODE}

Kegiatan magang dilaksanakan pada bulan Februari-Mei 2012 di Kebun Sumber Tengah, Desa Silo, Kecamatan Silo, Jember, Jawa Timur. Kegiatan magang meliputi seluruh kegiatan yang menyangkut aspek teknis di lapangan dan aspek manajerial teknis budidaya, diantaranya adalah kegiatan sensus tanaman, pembibitan, pemupukan, pengendalian penyakit, penyadapan, dan penanganan pascapanen. Kegiatan magang pada dua bulan berikutnya dilaksanakan sebagai pendamping mandor dan pendamping asisten kebun. Kegiatan yang berkaitan dengan aspek manajerial adalah mengawasi kerja karyawan, mengisi jurnal harian, membuat laporan harian, mingguan, dan bulanan.

Pengumpulan data yang dilaksanakan pada kegiatan magang menggunakan metode langsung (data primer) dan metode tidak langsung (data sekunder). Data primer yang diamati meliputi: kapasitas. Kegiatan pada bulan pertama adalah melaksanakan kegiatan seperti karyawan harian lepas (KHL) dan melaksanakan kegiatan di lapangan sesuai dengan kebutuhan kebun. Kegiatan-kegiatan yang dilaksanakan berkaitan dengan

penyadapan, klasifikasi penyadap, tingkat pemakaian kulit, penggunaan stimulan, kekeringan alur sadap, dan sistem pengangkutan.

a. Kapasitas penyadapan

Pengamatan dilakukan untuk memperoleh data jumlah tanaman yang mampu disadap/orang/hari. Pengamatan dilakukan pada tiga tahun tanam dengan tiap tahun tanam masing-masing diamati pada tiga orang penyadap.

b. Klasifikasi penyadap

Pengamatan dilakukan untuk memperoleh data hasil lateks, pemakaian kulit, dan kecepatan menyadap di lapangan berdasarkan tenaga kerja dilihat dari usia penyadapan, 
pendidikan, pengalaman kerja menyadap, dan kelas penyadap.

c. Tingkat pemakaian kulit

Pengamatan dilakukan pada 10 tanaman contoh untuk masing - masing penyadap. Hal hal yang diamati adalah sebagai berikut:

- Lingkar batang: diperoleh dengan mengukur lilit batang yang diukur $1 \mathrm{~m}$ dari kaki gajah.

- Tinggi alur sadap: mengukur tinggi sadapan bagian paling bawah menggunakan meteran diukur dari kaki gajah.

- Kedalaman sadap: menusuk kulit sisa sadapan menggunakan jangka sorong pada tiga titik, yaitu: bagian atas, tengah, dan bawah.

\section{d. Penggunaan stimulansia}

Dilakukan dengan melihat proses pengenceran, frekuensi pemberian, dosis stimulan per tanaman, merk dagang, bahan aktif, dan cara aplikasinya.

e. Kekeringan alur sadap

Dilakukan dengan melihat gejala tiap tanaman yang terkena gejala penyakit kekeringan alur sadap. Pengamatan dilakukan pada 50 tanaman contoh dari masing-masing tahun tanam pada afdeling yang diikuti penulis.

f. Sistem pengangkutan

Dilakukan dengan melihat jenis alat transportasi, kapasitas pengangkutan, dan waktu pengangkutan.

Pengumpulan data sekunder dilakukan dengan melakukan studi literatur di kantor kebun. Data sekunder yang dikumpulkan meliputi: struktur organisasi dan manajemen, sarana dan prasarana kebun, riwayat penggunaan dan karakteristik lahan, serta target dan realisasi produksi kebun.

Analisis data dilakukan dengan menggunakan perhitungan yaitu rataan dan standar deviasi, kecuali data produksi lateks penyadap dengan menggunakan uji t-student pada taraf 5\%. Untuk memperoleh t-hitung menggunakan rumus :

$$
\begin{gathered}
\text { t-student }=\frac{\left(\mathrm{x}_{1}+\mathrm{x}_{2}\right)}{\mathrm{sp} \sqrt{\left(\frac{1}{\mathrm{n}_{1}}\right)+\left(\frac{1}{\mathrm{n}_{2}}\right)}} \\
\mathrm{sp}=\sqrt{\frac{\left(\mathrm{n}_{1}-1\right) \mathrm{s}_{1}^{2}+\left(\mathrm{n}_{2}-1\right) \mathrm{s}_{2}{ }^{2}}{\mathrm{n}_{1}+\mathrm{n}_{2}-2}}
\end{gathered}
$$

$\mathrm{x}_{1} \quad$ : rata-rata produksi lateks penyadap kelas $\mathrm{B}$

$\mathrm{x}_{2}$ : rata-rata produksi lateks penyadap kelas $\mathrm{C}$

$\mathrm{s}_{1}{ }^{2}$ : ragam contoh 1

$\mathrm{s}_{2}{ }^{2} \quad$ : ragam contoh 2

sp : simpangan baku dari produksi lateks $\mathrm{n}_{1} \quad$ : jumlah produksi lateks penyadap kelas B $\mathrm{n}_{2} \quad$ : jumlah produksi lateks penyadap kelas $\mathrm{C}$

Hasil perhitungannya dibandingkan dengan t-tabel (Walpole, 1992). Apabila t-hitung berbeda di dalam wilayah kritik maka hasil pengamatan berbeda nyata. Sebaliknya, apabila thitung berbeda di luar wilayah kritik maka hasil pengamatan tidak berbeda nyata.

\section{HASIL DAN PEMBAHASAN}

\section{Keadaan Umum}

Iklim di lokasi kebun Sumber tengah mempunyai klasifikasi menurut SchmidthFerguson mempunyai tipe iklim $\mathrm{C}$ yaitu agak basah. Jumlah bulan basah sebanyak 7.1 bulan dan jumlah bulan kering sebanyak 4.1 bulan. Rata-rata curah hujan $2855 \mathrm{~mm} /$ tahun. Tanah di sekitar lokasi umumnya jenis regosol dan latosol dengan elevasi lahan berkisar antara 134-219 m dpl.

Luas areal kebun sebesar 961.42 ha dibagi menjadi dua afdeling, yaitu Sumber Jambe dan Gumitir. Total luas tanaman menghasilkan (TM) di Afdeling Sumber Jambe adalah 170.24 ha yang terdiri dari enam tahun tanam. Total luas TM di Afdeling Gumitir adalah 227.99 ha yang terdiri dari sepuluh tahun tanam.

Komposisi umur tanaman menghasilkan (TM) dapat dilihat pada Tabel 2. Sebanyak $82.51 \%$ dari total luas TM di Kebun Sumber Tengah adalah tanaman dengan umur lebih dari 24 tahun dengan produksi yang tergolong rendah. Hanya sebanyak $17.49 \%$ dari total luas TM di Kebun Sumber Tengah yang umur tanamannya antara 13-23 tahun dengan produksi yang masih cukup baik.

Berdasarkan data produksi Kebun Sumber Tengah selama lima tahun terakhir pada diketahui bahwa produktivitas cenderung menurun (Tabel 1). Rata-rata produktivitas Kebun Sumber Tengah lima tahun terakhir adalah $1044.80 \mathrm{~kg} / \mathrm{ha}$. Berdasarkan data dari Ditjenbun (2011) rata-rata produktivitas perkebunan besar negara lima tahun terakhir mulai dari tahun 2007-2011 adalah 1 $095.20 \mathrm{~kg} / \mathrm{ha}$. Hal ini menunjukkan bahwa ratarata produktivitas kebun sedikit dibawah rata-rata produktivitas perkebunan besar negara.

Tabel 1. Produktivitas kebun Sumber Tengah lima tahun terakhir

\begin{tabular}{cccc}
\hline Tahun & Luas (ha) & Produksi (kg) & Produktivitas (kg/ha) \\
\hline 2007 & 450.03 & 514314 & 1143 \\
2008 & 450.03 & 477079 & 1060 \\
2009 & 398.23 & 392335 & 985 \\
2010 & 377.73 & 385815 & 1021 \\
2011 & 377.73 & 383323 & 1015 \\
\hline
\end{tabular}


Sistem sadap yang digunakan pada Afdeling Sumber Jambe adalah cacah rucah (CCRC=sadap mati) pada tahun tanam 1977 dan 1979. Sistem sadap mati yaitu sistem sadap yang dilakukan pada tanaman yang akan dibongkar (replanting). Sistem sadap yang digunakan pada tahun tanam 1980, 1981, 1982, dan 1987 adalah sistem sadap double cutting (DC). Penyadapan double cutting (DC) merupakan metode penyadapan yang dilakukan secara bersamaan antara sadap ke arah bawah (SKB, $1 / 2 \mathrm{~S} \downarrow d / 3$ ) yaitu irisan sadapan setengah spiral ke bawah dengan interval penyadapan tiga hari sekali dan sadap ke arah atas (SKA, $1 / 4 \mathrm{~S} \uparrow \mathrm{d} / 3 . \mathrm{ET} 2.5 \%$.Ba.0.5.16./y $(2 \mathrm{w})$ ) yaitu irisan sadapan seperempat spiral ke atas dengan interval penyadapan tiga hari sekali menggunakan ethrel konsentrasi $2.5 \%$ dengan dosis 0.5 gram, aplikasi dilakukan 16 kali/tahun pada interval dua minggu sekali. Penyadapan DC dilakukan pada bidang sadap yang sama untuk mempertahankan tingkat produktivitas tanaman yang tinggi pada saat penyadapan telah menggunakan kulit pulihan. Rotasi yang digunakan di Afdeling Sumber Jambe yaitu tiga rotasi sadap.

Kegiatan penyadapan di Afdeling Sumber Jambe dilakukan mulai pukul 03.00 WIB tetapi pada kenyataan di lapangan terdapat beberapa tenaga sadap yang memulai penyadapan pukul 04.00 WIB. Pelaksanaan penyadapan dilakukan di bawah pengawasan mandor sadap yang berjumlah empat orang. Masing-masing mandor sadap membawahi setiap tahun tanam karet pada areal yang berbeda, yaitu tahun tanam 1977 dengan 1981, 1979 dengan 1987 sebelah timur, 1980, dan 1982 dengan 1987 sebelah barat.

\section{Kapasitas Penyadapan}

Kapasitas penyadapan merupakan kemampuan penyadap dalam menyadap pohon karet yang harus diselesaikan dalam satu hari. Jumlah pohon karet yang harus disadap harus disesuaikan dengan kemampuan penyadap. Ratarata populasi pohon di Afdeling Sumber Jambe dapat dilihat pada Tabel 2 yaitu sebanyak 222 pohon/hanca sedangkan rata-rata populasi pohon di Afdeling Gumitir sebanyak 399 pohon/hanca. Jumlah populasi pohon/hanca di Afdeling Gumitir lebih banyak karena komposisi umur pohon di Afdeling Gumitir lebih muda dibandingkan di Afdeling Sumber Jambe. Semakin muda komposisi umur pohon maka tingkat kesulitan menyadap lebih kecil dan waktu yang diperlukan untuk menyadap juga lebih cepat. Hal ini yang menyebabkan semakin muda komposisi umur pohon maka populasi pohon/hanca semakin banyak.

Rata-rata populasi pohon sebanyak 395 pohon/ha dan 311 pohon/hanca (Tabel 2). Pembagian jumlah hanca tersebut lebih kecil dari populasi pohon satu hektar. Populasi pohon seharusnya mencapai 500 pohon/ha tetapi pada kenyaaan di lapangan hanya mencapai 395 pohon/ha. Hal ini disebabkan oleh pohon sudah berumur tua sehingga sudah banyak pohon yang mati. Populasi tanaman ini lebih sedikit dari kebun PT Air Muring sebanyak 550 pohon/hanca (Asim, 2012). Hal tersebut disebabkan oleh komposisi umur pohon di Kebun Sumber Tengah sudah tua sehingga tingkat kesulitan untuk menyadap lebih besar. Tingkat kesulitan menyadap yang lebih besar menyebabkan pembagian pohon/hanca menjadi lebih sedikit untuk menyesuaikan dengan kemampuan penyadap dalam menyadap.

Tabel 2. Jumlah pohon pada beberapa tahun tanam

\begin{tabular}{|c|c|c|c|c|c|}
\hline \multirow{2}{*}{ Afdeling } & \multirow{2}{*}{ Tahun tanam } & \multirow{2}{*}{ Umur tanaman (tahun) } & \multirow{2}{*}{ Luas (ha) } & \multicolumn{2}{|c|}{ Jumlah pohon } \\
\hline & & & & Pohon/ha & Pohon/hanca \\
\hline \multirow{4}{*}{ Sumber Jambe } & 1980 & 32 & 40.57 & 377 & 222 \\
\hline & 1981 & 31 & 37.87 & 296 & 234 \\
\hline & 1982 & 30 & 36.39 & 366 & 211 \\
\hline & & \multicolumn{2}{|c|}{ Rata-rata } & 346 & 222 \\
\hline \multirow{5}{*}{ Gumitir } & 1990 & 22 & 19.00 & 428 & 405 \\
\hline & 1993 & 19 & 12.64 & 399 & 336 \\
\hline & 1995 & 17 & 19.00 & 502 & 455 \\
\hline & & \multicolumn{2}{|c|}{ Rata-rata } & 443 & 399 \\
\hline & & Rata-rata & & 395 & 311 \\
\hline
\end{tabular}

Tabel 3 dapat dilihat bahwa persentase pohon tersadap sebesar $90.98 \%$. Hal ini menunjukkan bahwa tidak semua pohon dalam hanca penyadap disadap oleh penyadap tetapi persentase pohon tersadap ini lebih besar dibandingkan persentase pohon tersadap di kebun
PT Air Muring yang sebesar $87 \%$ dari total jumlah pohon/hanca (Asim, 2012). Tidak semua pohon dalam hanca disadap oleh penyadap kerena alasan usia penyadap sudah tua sehingga kemampuan fisik juga menurun, maka dilakukan pembagian hanca ulang. Setiap hanca terdiri dari kurang lebih 
200-250 pohon pada tahun tanam yang sistem sadapnya menggunakan sistem sadap mati (tahun tanam 1977, 1979, 1980, dan 1981). Upaya yang dilakukan pihak Kebun Sumber Tengah untuk mengatasi hal tersebut selain pengurangan jumlah hanca juga dengan melakukan perekrutan tenaga sadap yang masih berusia produktif. Perekrutan tenaga sadap yang masih berusia produktif tersebut sudah dilakukan tetapi belum ada pelatihan khusus yang diberikan oleh pihak kebun kepada tenaga sadap tersebut. Tenaga sadap tersebut hanya diberikan areal tahun tanam yang menggunakan sistem sadap mati sehingga dapat terlebih dahulu mendapatkan pengalaman menyadap.

Tabel 3. Jumlah pohon tersadap pada beberapa tahun tanam

\begin{tabular}{ccccc}
\hline \multirow{2}{*}{ Tahun tanam } & \multirow{2}{*}{$\begin{array}{c}\text { Jumlah hanca } \\
\text { diamati }\end{array}$} & Pohon/hanca & Pohon disadap & \multicolumn{2}{c}{$\begin{array}{c}\text { Persentase pohon tersadap } \\
(\%)\end{array}$} \\
\cline { 3 - 4 } & 5 & 222 & 200 & 89.87 \\
1980 & 5 & 234 & 222 & 94.99 \\
1981 & 5 & 211 & 186 & 88.08 \\
\hline Rata-rata & 5 & $222 \pm 12$ & $203 \pm 18$ & 90.98 \\
\hline
\end{tabular}

\section{Klasifikasi Penyadap}

Penentuan kelas penyadap dilakukan setiap bulan sekali oleh tap control. Tap control adalah orang yang bertugas untuk mengontrol konsumsi kulit pohon karet yang disadap oleh penyadap. Setiap bulan kelas penyadap dapat berubah sesuai hasil penilaian tap control. Penentuan kelas sadap dilakukan berdasarkan penilaian-penilaian yang sudah disusun oleh pihak perusahaan dengan melihat berbagai kriteria. Kriteria yang dilihat untuk menentukan kelas penyadap adalah keterampilan dalam menyadap pohon karet. Nilai kelas penyadap dihitung berdasarkan toleransi kesalahan yang diperbolehkan pada saat menyadap.

Rata-rata pengalaman menyadap yang dimiliki penyadap pada tahun tanam 1987 adalah 34 tahun untuk kelas penyadap B dan 33 tahun untuk kelas penyadap C. Usia, pendidikan, dan pengalaman penyadap tidak menentukan kelas sadap (Tabel 4). Hal ini menunjukkan bahwa usia, pendidikan dan pengalaman menyadap tidak menentukan kelas penyadap. Adapun hal yang memengaruhi kelas sadap yaitu dari segi keterampilan menyadap antara kelas penyadap B dan kelas penyadap C. Kelas penyadap B memiliki kesalahan dalam proses menyadap lebih kecil dibandingkan dengan kelas penyadap $\mathrm{C}$.

Tabel 4. Kelas penyadap dilihat dari usia, pendidikan, dan pengalaman menyadap

\begin{tabular}{ccccc}
\hline Nama penyadap & Kelas sadap & Usia (tahun) & Pendidikan & Pengalaman menyadap (tahun) \\
\hline Nur Hadi & B & 52 & SD & 33 \\
Suwarno & B & 54 & SD & 36 \\
Amyati & B & 53 & SD & 34 \\
Mohir & B & 52 & SD & 33 \\
Dulgani & B & 52 & SD & 33 \\
\hline Rata-rata & & 53 & & 34 \\
\hline Suliha & C & 52 & SD & 32 \\
Hermanto & C & 51 & SD & 33 \\
Hakim & C & 50 & SD & 33 \\
\hline Rata-rata & & 51 & &
\end{tabular}

Tabel 5 dapat dilihat bahwa produksi lateks penyadap dengan kelas sadap B dan kelas sadap C berbeda nyata. Rata-rata produksi lateks kelas sadap B adalah 21.56 liter/hari sedangkan rata-rata kelas sadap C adalah 14.00 liter/hari. Hal ini menunjukkan bahwa kelas sadap mempengaruhi hasil lateks yang diperoleh oleh penyadap. Perbedaan hasil lateks yang diperoleh kelas penyadap B dan kelas penyadap C disebabkan oleh perbedaan keterampilan menyadap. Semakin kecil kesalahan dalam proses menyadap maka lateks yang dihasilkan akan semakin banyak.

\section{Tingkat Pemakaian Kulit}

Tabel 6 dapat dilihat bahwa konsumsi kulit pada panel bawah melebihi dari standar konsumsi kulit yang direkomendasikan oleh Balit Getas. Rata-rata konsumsi kulit pada panel bawah adalah $3.60 \mathrm{~mm}$ dengan simpangan baku sebesar 0.70 $\mathrm{mm}$. Konsumsi Kulit untuk penyadapan sadapan ke arah bawah (SKB) sebaiknya diusahakan 1.3$1.6 \mathrm{~mm} /$ irisan (Balit Getas, 2010). Penyadapan pada panel atas juga melebihi standar konsumsi kulit yang direkomendasikan oleh Balit Getas. Rata-rata konsumsi kulit pada panel atas adalah 
$5.10 \mathrm{~mm}$ dengan simpangan baku $0.30 \mathrm{~mm}$. Konsumsi kulit untuk penyadapan sadapan ke arah atas (SKA) sebaiknya diusahakan 2.1-2.5 mm/irisan (Balit Getas, 2010). Konsumsi kulit yang melebihi standar ini disebabkan oleh sitem sadap pada tahun tanam 1979 adalah sistem sadap mati. Pada periode ini produksi diekploitasi semaksimal mungkin, sehingga konsumsi kulit sulit untuk dikontrol. Kondisi bidang sadap yang sudah terletak pada posisi yang tinggi juga mempersulit pengontrolan konsumsi kulit. Konsumsi kulit pada panel atas sulit untuk dapat dikonrol karena terdapat tenaga penyadap menggunakan pisau pacekung atau pisau yang penggunaanya didorong. Seharusnya pisau yang digunakan untuk sadap atas adalah pisau biasa yang penggunaannya dengan cara ditarik dan pada saat menyadap menggunakan bantuan tangga.

Tabel 5. Produksi lateks berdasarkan kelas penyadap

\begin{tabular}{|c|c|c|c|c|c|}
\hline \multirow{2}{*}{ Nama Penyadap } & \multirow{2}{*}{ Kelas Sadap } & \multicolumn{3}{|c|}{ Produksi Lateks (liter/hari) } & \multirow{2}{*}{$\begin{array}{l}\text { Rata-Rata } \\
\text { (liter/hari) }\end{array}$} \\
\hline & & Hanca 1 & Hanca 2 & Hanca 3 & \\
\hline Nur Hadi & B & 22 & 20 & 22 & 21.33 \\
\hline Wiwik & B & 20 & 22 & 32 & 24.67 \\
\hline Amyati & B & 18 & 26 & 12 & 18.67 \\
\hline Rata-rata & & $20.00 \mathrm{a}$ & $22.67 \mathrm{a}$ & $22.00 \mathrm{a}$ & $21.56 \mathrm{a}$ \\
\hline Suliha & $\mathrm{C}$ & 18 & 13 & 20 & 17.00 \\
\hline Asis & $\mathrm{C}$ & 12 & 14 & 10 & 11.67 \\
\hline Narto & $\mathrm{C}$ & 11 & 13 & 16 & 13.33 \\
\hline Rata-rata & & $13.67 \mathrm{~b}$ & $13.67 \mathrm{~b}$ & $15.33 b$ & $14.00 \mathrm{~b}$ \\
\hline
\end{tabular}

Keterangan : Angka-angka yang diikuti huruf yang berbeda pada kolom yang sama menunjukkan perbedaan yang nyata menurut uji t-student pada taraf 5\%

Kedalaman irisan sadap yang dianjurkan adalah 1-1.5 mm dari lapisan kambium. Kulit pohon karet tersebut disisakan untuk menutupi lapisan kambium. Rusaknya lapisan kambium akibat penyadapan yang terlalu dalam akan menyebabkan kulit pulihan menjadi rusak. Rusaknya kulit pulihan akan menyebabkan tingkat kesulitan menyadap menjadi lebih tinggi dan dapat mengakibatkan berkurangnya produksi lateks (Damanik et al, 2010).

Tabel 6 dapat dilihat rata-rata kedalaman irisan sadap kelas penyadap B adalah 1.2 $\mathrm{mm} /$ sadap sedangkan rata-rata kedalaman irisan sadap kelas sadap C adalah $0.9 \mathrm{~mm} / \mathrm{sadap}$ diukur dari lapisan kambium. Kedalaman irisan sadap kelas penyadap $\mathrm{C}$ lebih dekat ke lapisan kambium dibandingkan kelas penyadap B. Hal ini menunjukkan bahwa kelas penyadap $\mathrm{C}$ lebih beresiko melukai lapisan kambium dari pada kelas penyadap B.

Sistem sadap pada tahun tanam 1979 adalah sistem sadap mati. Pada sistem sadap mati norma kedalaman irisan sadap tidak terlalu dilakukan pengawasan. Hal yang perlu dilakukan pengawasan pada sistem sadap mati adalah penyadapan tidak melukai kambium. Menurut Damanik et al. (2010) pada sadapan mati kedalaman irisan sadap harus kurang dari $1 \mathrm{~mm}$ diukur dari lapisan kambium. Penyadapan yang terlalu dangkal akan menyebabkan berkas pembuluh lateks yang terpotong sedikit. Jumlah berkas pembuluh lateks yang terpotong akan mempengaruhi jumlah lateks yang keluar. Semakin sedikit berkas pembuluh lateks yang terpotong maka semakin sedikit jumlah lateks yang keluar.

Tabel 6. Konsumsi kulit beberapa penyadap di tahun tanam 1979

\begin{tabular}{|c|c|c|c|c|c|c|c|c|}
\hline \multirow{2}{*}{$\begin{array}{c}\text { Nama } \\
\text { penyadap }\end{array}$} & \multirow{2}{*}{$\begin{array}{l}\text { Kelas } \\
\text { sadap }\end{array}$} & \multirow{2}{*}{$\begin{array}{l}\text { Lilit } \\
\text { batang } \\
(\mathrm{cm})\end{array}$} & \multicolumn{2}{|c|}{ Tinggi alur sadap (cm) } & \multicolumn{2}{|c|}{$\begin{array}{l}\text { Konsumsi kulit sadap } \\
\text { (mm/sadap) }\end{array}$} & \multirow{2}{*}{$\begin{array}{l}\text { Kedalaman Irisan } \\
\text { sadap (mm/sadap) }\end{array}$} & \multirow{2}{*}{$\begin{array}{c}\text { Waktu } \\
\text { (menit/sadap) }\end{array}$} \\
\hline & & & Panel B2-2 & Panel H0-2 & Panel B2-2 & Panel H0-2 & & \\
\hline Nur Hadi & $\mathrm{B}$ & 88.17 & 93.33 & 222.33 & 4.50 & 5.20 & 1.2 & 1.97 \\
\hline Wiwik & B & 93.33 & 69.00 & 226.33 & 2.90 & 4.60 & 1.2 & 2.24 \\
\hline Amyati & B & 86.67 & 34.67 & 215.67 & 2.80 & 5.20 & 1.2 & 3.07 \\
\hline Suliha & $\mathrm{C}$ & 91.67 & 46.00 & 274.00 & 4.10 & 5.40 & 0.8 & 5.42 \\
\hline Asis & $\mathrm{C}$ & 93.33 & 41.00 & 240.33 & 3.50 & 4.90 & 1.0 & 3.35 \\
\hline Rata-rata & & 90.63 & 56.80 & 235.73 & 3.60 & 5.10 & 1.1 & 3.21 \\
\hline STD & & 3.06 & 24.18 & 23.22 & 0.70 & 0.30 & 0.2 & 1.36 \\
\hline
\end{tabular}

Penggunaan Stimulansia

Penggunaan stimulansia bertujuan untuk menghambat pembentukan sumbat pembuluh lateks pada ujung sel yang terpotong, sehingga lateks mengalir lebih lama. Pada batas tertentu penggunaan stimulansia dapat meningkatkan produksi, tetapi penggunaan yang berlebihan dapat 
mempercepat terjadinya kekeringan alur sadap (KAS). Stimulansia yang digunakan terdiri dari stimulansia cair dan stimulansia gas. Mekanisme kerja stimulansia gas hampir sama dengan stimulansia cair. Perbedaan stimulansia gas dengan stimulansia cair yaitu gas etilen baru tersedia setelah etefon dihidrolisis terlebih dahulu di dalam jaringan tanaman.

Stimulansia cair yang digunakan pada Kebun Sumber Tengah dengan merk Ethrel dan Amcotrel. Stimulansia ini berbahan aktif etefon $10 \%$. Dosis yang digunakan sebanyak 1 $\mathrm{g} /$ pohon/bulan. Ketepatan dosis yang digunakan sudah sesuai standar sistem penyadapan yaitu, $1 / 4 \mathrm{~S} \uparrow \mathrm{d} / 3$. ET2.5\%. Ba.0.5.16./y (2w). Pengamatan langsung di lapangan menunjukkan bahwa tidak dilakukan kalibrasi pengukuran dosis stimulansia sebelum dilakukan aplikasi stimulansia pada pohon karet. Hal ini dapat mengakibatkan dosis stimulansia yang digunakan tidak sesuai dengan rekomendasi perusahaan. Ketepatan waktu aplikasi stimulansia juga belum sesuai dengan sistem sadap yang digunakan karena seharusnya aplikasi stimulansia dilakukan dua minggu sekali selama 16 kali per tahun. Cara aplikasi stimulansia adalah secara bark aplication (Ba) pada panel atas, sedangkan pada panel bawah tidak perlu diaplikasikan stimulansia.

Stimulansia gas yang digunakan pada Kebun Sumber Tengah ber-merk Latene. Pada pengamatan di lapangan, terdapat beberapa aplikasi stimulansia gas yang tidak sesuai dengan standar. Terdapat beberapa pohon yang diaplikasikan stimulansia gas bukan pada kulit perawan di panel atas, selain itu terdapat stimulansia gas yang diaplikasikan pada pohon yang kondisi daunnya kurang sehat dan memiliki lilit batang $<60 \mathrm{~cm}$.

\section{Kekeringan Alur Sadap}

KAS pada tanaman karet dimulai dengan munculnya gejala awal yaitu terjadi KAS parsial. Lateks yang terkena KAS parsial hanya keluar pada titik-titik tertentu saja karena pada kondisi tersebut mulai muncul sel-sel batu yang dapat menyumbat aliran lateks. Apabila KAS persial berlangsung cukup lama maka selanjutnya lateks tidak akan keluar sama sekali atau disebut KAS total. Gejala KAS menunjukkan bahwa pohon telah mengalami kelelahan secara fisiologis. Pengamatan KAS dilakukan pada KAS total karena gejala KAS parsial sulit untuk diamati. Menurut Anwar (2001) KAS mengakibatkan pohon karet tidak mengalirkan lateks, tetapi KAS tidak mematikan tanaman. Gejala KAS dimulai dengan tidak mengalirnya lateks pada sebagian alur sadap sehingga alur sadap akan menjadi kering. Bagian yang kering akan berubah warna menjadi cokelat karena pada bagian ini terbentuk benjolan. Kekeringan kulit tersebut dapat meluas ke kulit lainnya pada satu panel sadap, tetapi tidak meluas dari kulit perawan ke kulit pulihan atau sebaliknya. Menurut Damanik et al. (2010) KAS bukan disebabkan oleh infeksi mikroorganisme melainkan karena penyadapan yang terlalu sering, apalagi jika disertai penggunaan bahan perangsang lateks (stimulansia). Beberapa upaya pengendalian yang dapat dilakukan yaitu dengan mengurangi penggunaan bahan perangsang sadap, jangan melakukan penyadapan terlalu sering selain itu tanaman yang kulitnya tidak bisa disadap lagi sebaiknya tidak disadap.

Pohon yang terkena KAS pada Afdeling Sumber Jambe adalah sebanyak $6 \%$ dari populasi dengan simpangan baku sebesar 3.35\% (Tabel 7). Kejadian KAS di Afdeling Sumber Jambe lebih besar dibandingkan kebun PT Air Muring yang hanya sebesar 2.72\% (Asim, 2012). Berdasarkan Balit Getas (2011) aplikasi stimulansia dikurangi pada tingkat serangan KAS lebih dari $5 \%$ dan aplikasi stimulansia harus dihentikan apabila tingkat serangan KAS lebih dari $10 \%$. Sumardji (2001) menyatakan bahwa secara umum kejadian KAS yang terjadi di PTP Nusantara berkisar 5$25 \%$ terhadap populasi menghasilkan.

Semakin banyak pohon yang terkena KAS maka jumlah pohon yang dapat disadap oleh penyadap semakin sedikit. Pohon karet yang terkena KAS tidak disadap oleh penyadap karena pohon tersebut mengalami kelelahan fisiologis sehingga tidak atau hanya sedikit mengeluarkan lateks jika dilakukan penyadapan. Banyaknya pohon yang terkena KAS ini dapat disebabkan oleh intensitas penyadapan yang berlebihan (over exploitation) dan penggunaan stimulansia yang melebihi standar. Upaya yang dilakukan untuk mengatasi masalah tersebut adalah dengan mengistirahatkan pohon karet sampai pohon karet tersebut dapat mengeluarkan lateks kembali.

Tabel 7. Tingkat Serangan KAS pada beberapa tahun tanam

\begin{tabular}{cccc}
\hline $\begin{array}{c}\text { Tahun } \\
\text { tanam }\end{array}$ & $\begin{array}{c}\text { Jumlah pohon } \\
\text { diamati }\end{array}$ & $\begin{array}{c}\text { Pohon terserang } \\
\text { KAS (pohon) }\end{array}$ & $\begin{array}{c}\text { Persentase } \\
(\%)\end{array}$ \\
\hline 1977 & 50 & 5 & 10 \\
1979 & 50 & 5 & 10 \\
1980 & 50 & 2 & 4 \\
1981 & 50 & 2 & 4 \\
1982 & 50 & 3 & 6 \\
1987 & 50 & 1 & 2 \\
\hline Rata-rata & 50 & $3 \pm 1.67$ & $6 \pm 3.35$ \\
\hline
\end{tabular}


Sistem Pengangkutan

Pengambilan lateks dan lump pada masingmasing hanca di kebun dilakukan pada pukul 09.30 WIB namun pada kenyataannya beberapa penyadap mengambil lateks dan lump lebih cepat dari waktu yang telah ditentukan. Hal ini menyebabkan masih terdapat banyak tetes lanjut lateks yang tidak diambil pada hari itu sehingga akan menjadi lump pada hari selanjutnya. Kebiasaan buruk yang dilakukan para penyadap ini menyebabkan produksi lateks menurun.
Beberapa permasalahan lainnya yang terjadi di lapang yaitu mengenai pengukuran nilai kadar karet kering (KKK) dan kondisi jalan yang rusak. Pengukuran KKK tidak dilakukan terhadap setiap penyadap tetapi dilakukan berdasarkan setiap tahun tanam sehingga akan merugikan penyadap yang menghasilkan lateks dengan KKK yang tinggi. Kondisi jalan yang rusak menyebabkan truk tidak dapat masuk ke beberapa bagian kebun sehingga pengangkutan dilakukan dengan mobil bak terbuka. Perhitungan rata-rata produksi lateks dan lump serta kapasitas pengangkutan di Afdeling Sumber Jambe adalah sebagai berikut:

$$
\begin{aligned}
\text { Rata-rata produksi lateks } & =\frac{(\text { jumlah lateks bulan Februari }+ \text { Maret }+ \text { April })}{(\text { jumlah hari })} \\
& =\frac{(56043+55631+65089)}{(29+31+30)} \\
& =1996 \text { liter/hari } \\
\text { Rata-rata produksi lump } & =\frac{(\text { jumlah lump bulan Februari }+ \text { Maret }+ \text { April })}{(\text { jumlah hari })} \\
& =\frac{(9189+8704+12 \text { 276 })}{(29+31+30)} \\
& =336 \mathrm{~kg} / \text { hari } \\
\text { Kapasitas pengangkutan } & =(\text { kapasitas truk } \times 2 \text { truk })+\text { kapasitas mobil } \\
& =(((27 \text { bowl } 33 \text { liter })+\text { tong } 200 \mathrm{~kg}) \times 2)+((18 \text { bowl } \times 33 \text { liter })+(\text { tong } 50 \mathrm{~kg})) \\
& =((891 \text { liter }+200 \mathrm{~kg}) \times 2)+(594 \text { liter }+50 \mathrm{~kg}) \\
& =2376 \text { liter lateks/hari dan } 450 \mathrm{~kg} \text { lump/hari }
\end{aligned}
$$

Di Afdeling Sumber Jambe pengangkutan bahan olah karet dari TPH ke pabrik pengolahan karet dilakukan dengan menggunakan dua truk dan satu mobil bak terbuka. Dari hasil perhitungan di atas terlihat bahwa rata-rata produksi lateks dan lump yaitu 1996 liter/hari dan 336 kg/hari sedangkan kapasitas pengangkutan maksimal yang dapat dilakukan yaitu 2376 liter lateks/hari dan $450 \mathrm{~kg}$ lump/hari. Hal ini menunjukkan bahwa kapasitas pengangkutan lateks dan lump di Afdeling Sumber Jambe sudah cukup.

\section{KESIMPULAN}

Sistem penyadapan tanaman karet yang dilakukan di Kebun Sumber Tengah sudah cukup baik mulai dari kapasitas penyadapan sampai sistem pengangkutan. Rata-rata populasi di Kebun Sumber Tengah yaitu 311 pohon/hanca. Tingkat kesulitan menyadap yang lebih besar karena umur tanaman sudah tua menyebabkan populasi pohon/hanca menjadi lebih sedikit untuk menyesuaikan dengan kemampuan penyadap. Rata-rata persentase pohon tersadap di Afdeling Sumber Jambe yaitu $90.98 \%$. Usia, pendidikan, dan pengalaman penyadap tidak menentukan kelas sadap. Kedalaman sadap di Afdeling Sumber Jambe yaitu 0.9-1.2 $\mathrm{mm} / \mathrm{sadap}$ sudah sesuai dengan rekomendasi dari Balit Getas yaitu 1-1.5 $\mathrm{mm} / \mathrm{sadap}$. Ketepatan dosis stimulansia cair yang digunakan di Afdeling Sumber Jambe sudah sesuai standar yang dianjurkan yaitu $1 \mathrm{~g} /$ pohon/bulan tetapi ketepatan waktu aplikasi belum sesuai dengan sistem sadap yang digunakan. Terdapat beberapa aplikasi stimulansia gas yang tidak sesuai dengan standar.

\section{DAFTAR PUSTAKA}

Anwar, C. 2001. Manajemen dan Teknologi Budidaya Karet. Medan (ID): Pusat Penelitian Karet.

Asim, M. 2012. Penyadapan Karet (Hevea brasilliensis Muell Arg.) di PT Air Muring, Bengkulu [Skripsi]. Bogor (ID): Institut Pertanian Bogor.

[Balit Getas] Balai Penelitian Getas. 2010. Evaluasi dan Rekomendasi Sistem Eksploitasi Kebun Karet PT Perkebunan Nusantara XII. Balai Penelitian Getas. 
[Balit Getas] Balai Penelitian Getas. 2011. Laporan Akhir Pengawalan Sistem Eksploitasi Tanaman Karet PT Perkebunan Nusantara XII (Persero) Kebun Sumber Tengah. Balai Penelitian Getas. Salatiga.

Damanik, S., Syakir, M., Tasma, M., Siswanto. 2010. Budidaya dan Pasca Panen Karet. Pusat Penelitian dan Pengembangan Perkebunan. Bogor(ID): Eska Media.

Direktorat Jenderal Perkebunan. 2011. Statistik Perkebunan Indonesia 2008-2011. Direktorat Jenderal Perkebunan. Jakarta (ID): Departemen Pertanian.

Heru, D.S., Andoko, A. 2010. Petunjuk Lengkap Budidaya Karet. Jakarta (ID): PT. Agromedia Pustaka.
Polhamus, L.G. 1962. Production of rubber from hevea. In N. Polunin $(E d)$. Rubber Botany, Production, and Utilization. New York (USA): Interscience Publisher Inc.

Setyamidjaja, D. 1993. Seri Budidaya Karet. Yogyakarta (ID): Kanisisus.

Sumarmadji. 2001. Sistem eksploitasi tanaman karet yang spesifik-diskriminatif. Warta Pusat Penelitian Karet. 19 (1-3).

Tarmizi, A. 2007. Faktor-faktor yang mempengaruhi efisiensi saluran pemasaran karet rakyat di jambi. Jurnal Aplikasi Manajemen 5(3):412-417.

Walpole, R. E. 1992. Pengantar Statistika. Edisi ke-3. Jakarta. (ID): PT Gramedia Pustaka Utama. 